\title{
Contract Research Organization
}

National Cancer Institute

\section{Source}

National Cancer Institute. Contract Research Organization. NCI Thesaurus. Code C54148.

A commercial organization contracted by a client to perform one or more researchrelated functions. 